\title{
From the Special Issue Editors: Technology Commercialization and Entrepreneurship*
}

\author{
Robert E. Litan and Michael Song
}

\section{Introduction}

$\mathrm{F}$ or more than 40 years, it has been well understood that, at least for economies at the technological frontier such as the United States, technological advances have been the most important driver of economic growth. But technological improvements by themselves do not contribute to growth unless they are somehow commercialized, whether in the form of new products and services, or integrated as part of the production or service delivery process.

Commercialization, in turn, can be accomplished by existing firms or by new entrants. Anecdotal evidence suggests that the different matters, confirming an insight of Joseph Schumpeter nearly a century ago: Entrepreneurs, with little or no stake in the status quo, seem to be responsible for a disproportionate share of "radical" innovations (i.e., those that substantially disrupt the way things are currently done), whereas large, existing firms seem to have a comparative advantage in introducing more incremental innovations that refine what already exists. Both types of innovation (radical and incremental) as well as both types of firms (existing and new) are essential in modern economies (Baumol, 1992; Baumol, Litan, and Schramm, 2007).

The articles in this volume seek to advance our understanding of how technological advances are commercialized. The first three do so in a developed country context, primarily the United States; the

\footnotetext{
* Robert E. Litan is vice president for Research and Policy at the Kauffman Foundation and senior fellow in the Economic Studies and Global Economics at the Brookings Institution. Michael Song is the Charles N. Kimball, MRI/Missouri Endowed Chair in Management of Technology and Innovation and professor of marketing at the Bloch School of Business at the University of Missouri-Kansas City.

The editors wish to thank the Ewing Marion Kauffman Foundation for providing financial support for this special issue and the research conference that was held in November 2006.
}

latter two examine this question in the Chinese context. The comparison between United States and China is deliberate. The United States is a frontier economy; China is an up-and-coming challenger, thought by many to be on the leading edge of change in the 21 st century. The contrasting experiences should be useful to practitioners and researchers alike. In the balance of this introductory chapter, we summarize the main insights of each of the papers.

\section{Summaries}

All of the papers in this volume focus, in one way or another, on a particular type of entrepreneurship - new firms in which the business model is strongly rooted in the development of application of a new technology. However, such net technology ventures (NTVs) have a limited survival rate. In the first article, Michael Song, Ksenia Podoynitsyna, Hans van der Bij, and Johannes I. M. Halman report a longitudinal study of 11,259 new technology ventures established between 1991 and 2000 in the United States. They find that of 11,259 NTVs, only 36 percent had more than five employees and were still in operation four years after launch. By the five-year mark, only 22 percent of the companies had this level of employment and had survived.

The authors also report the results of their metaanalysis of the academic literature to determine which factors best account for NTV success. Specifically, the authors reviewed 31 papers on this subject, drawing out 24 success factors from them.

After correcting for various statistical issues, the authors find that 8 of the 24 factors are most highly correlated with NTV success, using Pearson rank correlations: the ability to integrate supply chains, market scope, firm age, age of founding team, financial resources, founders' marketing experience, founders' 
industry experience, and existence of patent protection. Notably, the authors find from their analysis that a number of popularly mentioned success factors are not significantly associated with NTV success: founders' experience in research and development, founders' prior start-up experience, various business environmental variables, and the intensity of competition (or lack thereof). For the remaining factors, the authors conducted a moderator analysis and found that about half of these were evenly split between being associated with NTV success and this not being the case.

To be sure, there are limits to any meta-analysis, which is only as good as the studies that make up the analysis. Further, this particular study extends only through 2000, or the year in which the Internet bubble burst. Future studies will determine whether the results reported in this article hold up.

One of the challenges confronting any business undertaking a new venture is to cope with uncertainty and thus the unknown. How much better off founders of new companies and managers of existing ones would be therefore if they could somehow anticipate and react to the unknown factors that will influence their success? In the second article, Christoph Loch, Michael Solt, and Elaine Bailey lay out a process by which firms can identify and ideally react to what the authors call the "unknown unknowns" or "unforeseeable uncertainties."

The authors begin by drawing the traditional distinction between risk, which can be measured because the probabilities of different possible outcomes are known, and Knightian uncertainty, in which the probabilities are not known. Yet even this definition of uncertainty assumes that the relevant factors and variables that may affect an outcome, as well as the causal relationships between them, are known. Those undertaking a new venture, however, must confront even greater uncertainty arising from an inability to recognize or know the relevant variables and their relationships to possible outcomes. The authors note that this higher level of uncertainty has been given various terms-unforeseen contingencies, wicked problems, or unknown unknowns - and it is this difficult subject to which they devote their attention.

Traditional models of project risk managementwhich specify different outcomes and their probabilities - do not account for the unknown unknowns, which can be especially problematic when a new venture is attempting to develop or use radically new and therefore untested technology. The authors outline two possible ways that firms can account for the unknown unknowns: The first is selectionism, or pursuing in parallel fashion multiple approaches to solving a problem and seeing what works and what does not; this method is sometimes used by pharmaceutical companies testing different molecules or, in the case of new ventures, trying several different user interfaces or marketing messages. The second is probing and learning, or learning and adjusting over time. Choosing between these two approaches is a central challenge facing anyone undertaking a new venture, with the outcome depending on the magnitude of the unforeseeable uncertainties and the complexity of the initiative. The authors consider a range of alternatives and their implications.

But how can those undertaking new ventures diagnose or determine the significance of the unknown unknowns, especially when it may not be possible to do so with any accuracy at the outset of a particular project? The authors suggest that the reasonable course is to break down the venture into various components (e.g., technology, the market, the regulatory environment) and to assess how each might be affected by unforeseeable uncertainty. They apply their approach to the experience of a Silicon Valley start-up, Escend Technologies, in which the chief executive officer (CEO) is one of the article's coauthors, Bailey.

Escend was formed in 1999 with the aim of enabling semiconductor and electronic component manufacturers to connect and collaborate with their sales representatives, who sold these items to original equipment manufacturers (OEMs) in the electronics business. Due to changing market conditions and customer needs, Escend changed its business model several times but, nonetheless, through its first four years continued to lose money, despite having raised \$16 million in venture funding. By 2003, the company was clearly in need of a capital infusion, and Bailey was brought on as an interim CEO while her venture capital firm decided whether to provide another round of financing.

After investigating the company's difficulties, Bailey broke down the subproblems and identified some immediate measures to save the company: among them, reducing head count to slow the cash burn rate. Bailey also mapped out the various uncertainties or unknowns the company faced, including uncertainty about what precisely customers most wanted, which created uncertainty about the nature of the appropriate technology. Key to this process of discovery was to let the unknown unknowns emerge as measures were taken to stabilize Escend's finances. A plan for 
redirecting the company was developed out of this probing and learning process, and another round of financing from venture capitalists was secured.

The authors conclude their article with a detailed analysis of how Bailey and her management team identified various subproblems, with different types and degrees of uncertainty, and developed subprojects and solutions to address them. Throughout this process of learning by doing, the team faced a series of new uncertainties and challenges. In this respect, Escend's experience surely mirrors that of many, if not most, start-ups and ongoing ventures.

Prior studies suggest that there are important differences between academic and corporate inventors, particularly with respect to technology management. In the third article, Bradley L. Golish, Mary E. Besterfield-Sacre, and Larry J. Shuman examine different technology development approaches taken by academic and corporate inventors in the United States.

The authors conducted a series of structured interviews with academic and corporate innovators to get at this issue, asking each innovator to describe the process map used to develop their particular technology. These interviews uncovered several differences between academic and corporate inventors.

First, academic inventors tend to focus primarily on technological issues and to use significantly less elements in their process maps than do their corporate counterparts. Second, there is little commonality among elements on the academic maps, suggesting that academic inventors tend to do things differently from one another. Third, corporate inventors tend to pay more attention to financial issues than academic inventors. Fourth, nearly 30 percent of the elements on the corporate inventors' maps are common, and 20 percent of all the elements on their maps are not used by any of the academic inventors (and most of these elements are nontechnical in nature).

The authors conclude that academic inventors tend to ignore financial or market considerations in their activities. For this reason, universities that employ academic inventors would be better positioned to benefit from patents if these inventors paid more attention to customer demands and needs.

Whereas as the first three articles in the volume largely concentrate on technology commercialization in the United States, the last two articles focus on this activity in the world's most dynamic economy, China.

Yuan Li, Hai Guo, Yi Liu, and Mingfang Li focus on entrepreneurial orientation (EO) of Chinese firms and its relationship to the commercialization of technology in China. The authors note that prior studies of EO have concentrated on its role in developed economies. Their study, in contrast, takes the analysis to the world's largest developing economy, where formerly state-owned enterprises (SOEs) have been partially privatized, in large measure by enabling CEOs and other managers to own some portion of the equity of the enterprises. The authors use a data base of approximately 600 Chinese firms to test two key hypotheses: (1) whether and how organizational incentives - especially CEO ownership and CEO turnoveraffect the EO of the Chinese firms; and (2) whether EO in turn in any way is related to the propensity of firms to commercialize new technologies.

In theory, there is reason to believe that there is a positive connection between CEO ownership and a firm's propensity to take risks - that is, to be entrepreneurial. Ownership aligns the personal incentives of the CEO with the performance of the firm. Since the CEO stands to gain from risk taking by the firm, other things being equal, firms in which CEOs own a significant share of the capital should therefore be entrepreneurial than those where the CEO is simply a manager.

The connection between CEO turnover and a firm's EO, at least at the theoretical level, is more ambiguous. Agency theory might suggest that shortterm CEO tenure would dampen the firm's propensity to be entrepreneurial, since CEOs expecting to turn over quickly could be tempted to engage in more self-centered and short-term behavior. On the other hand, CEOs who move from job to job are more likely to learn from competitors, and this should enhance their propensity to take prudent risks. The authors posit a third possibility: that there is an inverse $\mathrm{U}$ relationship between CEO turnover frequency and firm EO. The thought here is that low and high turnover may be inimical to entrepreneurship but that at some middle level of turnover frequency CEOs are at a happy medium, where they are sufficiently comfortable with their firm and knowledge of its challenges that they can take prudent risks but not serving such a long term that they will have lost the desire to take risks.

The authors make out a more straightforward case, again in theory, for a positive link between a firm's EO and its propensity to be involved in the commercialization of new technologies. Further, they argue from first principles that as technology in a particular sector changes more rapidly - in other words, as technological turbulence increases - the more interested firms should be commercializing new technologies. 
If this were not true, then the firm's continued existence would be put in doubt.

The authors' database used to test these various hypotheses contains firms from seven Chinese provinces and the municipality of Shanghai. The data cover the 1997-2001 time period, or the time frame in which significant reforms of management incentives were implemented as part of the Ninth Five Year Development Plan in China. The authors measured CEO ownership by the fraction of a firm's shares that were owned by the CEO; CEO turnover by the number of $\mathrm{CEO}$ replacements during the five year period; entrepreneurial orientation based on a seven-point scale determined by the firm's emphasis on research and development (R\&D), tendency to undertake highrisk, high-return projects, and four other factors; technological turbulence by four factors related to the pace of technological change in a sector; and technology commercialization by a seven-point scale based on a number of items, including numbers of patents and the extent to which the technologies underlying them are developed into products.

The results of the authors' analysis broadly confirmed their hypotheses. There is, in fact, a positive relationship between both CEO ownership the entrepreneurial orientation of the firms in their sample. The data also confirm the presence of the hypothesized inverse $U$ relationship between the frequency of CEO turnover and EO. And there is, indeed, as one might expect, a positive relationship between a firm's EO and its propensity to engage in the commercialization of new technologies.

The Chinese economy is being rapidly transformed not only by the partial privatization of the former SOEs but also by the proliferation of new, smaller firms. Wai-sum Siu and Qiong Bao examine in the final article the network strategies of small Chinese high-technology firms.

The importance of networking by entrepreneurs, with other entrepreneurs and sources of capital, is widely recognized. China is no exception, although there appears to be debate about the relevant trends. Some contend that business actors are paying more attention to more objective considerations as price and quality of products than to social relationships they may have. Others have a different view, namely that interpersonal relationships continue to have an important impact on the way business is conducted.

To help resolve this debate, Siu and Bao report findings from multiple case studies, from 12 entrepreneurial firms at three different (but early) points in their life cycles. The cases were developed largely through extensive interviews and were selected through the authors' personal network of hightechnology firms in two of the most technologically dynamic parts of China, Beijing and Shenzen. The authors defend their choice of the two geographic areas in several ways, noting that of the roughly 22,000 high-technology firms in China, about 15,000 are located in Beijing. Shenzen was added to the analysis because of its role as the first special economic zone, its strong economic development track record, and its relatively open political environment. Both areas of the country attract many people from other parts of China to establish new business ventures.

The interviews revealed two different types of networks: (1) those that are based on collaboration between the parties to advance a common end; and (2) those based on transactions, where one party typically seeks to piggyback on the economic power of the other. Clearly, the transaction networks are weaker than the collaboration networks. Entrepreneurs may choose one or the other type of network but often will use both types, depending on the need. For example, in designing new products, a product-based entrepreneur would want close collaboration with its suppliers, designers, and manufacturers. But in the actual purchasing of suppliers, the same entrepreneur may find a useful transaction-based partner. Or the product entrepreneur may seek shorter-term transaction-based relationships with particular design houses so as not to become overly dependent on a single one.

Not surprisingly, personal trust plays an important role in all networks. One entrepreneur pointed to his relationships with other university alumni (a consideration present in developed economies as well). Some networks develop so that the parties become interdependent - that is, the relationship becomes essential for both (or more) parties to survive. Networks and relationships can and often do change as firms evolve; firms also find themselves entering or forming new networks as conditions warrant. The authors provide numerous examples that demonstrate these findings.

Collectively, the articles in this volume advance our understanding of the forces driving firms to commercialize new technologies and the factors that drive their success. In addition, the articles on China provide a much closer look than has heretofore been available at the factors influencing the success and nature of operations of both large, former SOEs and the new technologically oriented firms springing up all over China. 
Certain conclusions from the articles on China should resonate with researchers and entrepreneurs in developed economies. Ownership of firms by their leaders makes a difference to firm performance in China, as one would expect it to in more developed settings. Moreover, the networks of the founders of new ventures in China are found to be similar to those present in the developed economies.

In short, though entrepreneurs in different parts of the world must shape their businesses to adapt to local laws, mores, and cultures, the forces driving their success - ownership and networking - may be common to successful entrepreneurial behavior throughout the world.

\section{References}

Baumol, William J. (1992). The Free Market Innovation Machine. Princeton, NJ: Princeton University Press.

Baumol, William J., Litan, Robert E., and Schramm, Carl (2007). Good Capitalism, Bad Capitalism, and the Economics of Growth and Prosperity. New Haven, CT: Yale University Press. 